
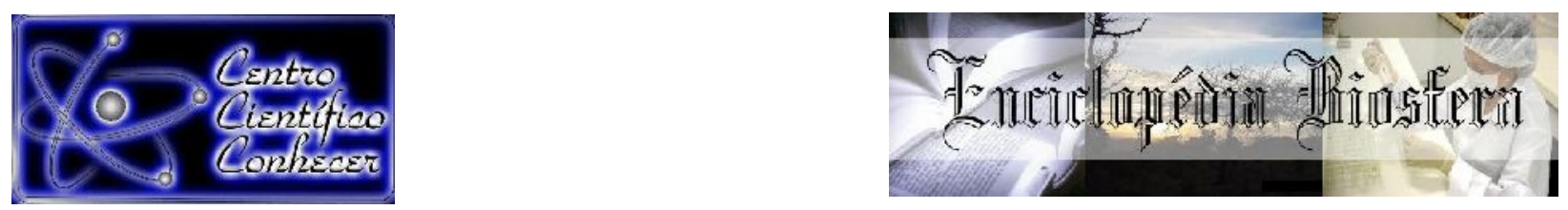

\title{
COMPOSIÇÃO FLORÍSTICA E ANÁLISE PAISAGÍSTICA DA PRAÇA DUQUE DE CAXIAS NO MUNICÍPIO DE CÁCERES-MT
}

\section{Camila Souza da Silva $^{1}$, Fernanda Miguel Franco ${ }^{2}$, Arthur Guilherme Schirmbeck $^{k}$ Chaves $^{3}$}

${ }^{1}$ Mestranda do Programa de Pós-Graduação em Ambiente e Sistema de Produção Agrícola da Universidade Estadual do Mato Grosso (camilaengftal@gmail.com) Tangará da Serra, MT - Brasil

${ }^{2}$ Prof. ${ }^{\text {a }}$ Dr. Instituto Federal de Educação, Ciências e Tecnologia de Mato Grosso Cáceres-MT- Brasil

${ }^{3}$ Prof. Mestre Instituto Federal de Educação, Ciências e Tecnologia de Mato Grosso - Cáceres, MT - Brasil

Recebido em: 22/09/2018 - Aprovado em: 23/11/2018 - Publicado em: 03/12/2018 DOI: 10.18677/EnciBio_2018B27

\begin{abstract}
A arborização de praças desempenha papel fundamental no contexto urbano, principalmente relacionado ao conforto dos usuários, além de contribuir com a beleza cênica do local. O presente trabalho teve como objetivo analisar a qualidade ambiental e cênica da Praça Duque de Caxias, na cidade de Cáceres-MT, através de um levantamento florístico e análise paisagística. Foi realizado levantamento florístico com o intuito de listar todas as espécies vegetais presentes na área. As informações foram registradas em planilhas contendo nome vulgar, nome científico, porte das árvores (pequeno, médio e grande) e origem (nativa ou exótica). A análise paisagística foi realizada através de observação da inserção de mobiliários, característica das espécies arbóreas e o revestimento do solo. Na praça existem 69 indivíduos de 18 espécies diferentes, sendo 66,7\% de origem exóticas, no entanto é aconselhável sempre o predomínio de uso de espécies nativas. As espécies com maior frequência foram: Licania tomentosa (Benth.) Fritsch (oiti), Delonix regia (Bojer ex Hook.) Raf. (flamboyant) e Roystonea oleracea (Jacq.) O.F. Cook (palmeira imperial). A distribuição das árvores na praça se dá tanto de forma isolada como agrupada, logo, possui áreas densamente sombreadas, como também áreas em que os bancos estão expostos à radiação solar, o que determina a sua utilização pela população. Dessa forma, sugere-se que sejam plantadas árvores nativas em locais com ausência de vegetação visando proporcionar sombra aos usuários, de modo que torne a praça mais frequentada.
\end{abstract}

RESUMO

PALAVRAS-CHAVE: Áreas verdes; Inventário florístico; Praças públicas.

\section{FLORISTIC COMPOSITION AND LANDSCAPE ANALYSIS OF DUQUE DE CAXIAS SQUARE IN CÁCERES-MT}

\begin{abstract}
ABSTRAT
The arborization of squares plays a fundamental role in the urban context, mainly related to the comfort of the users, besides contributing with the scenic beauty. The objective of this work was to analyze the environmental and scenic quality of the
\end{abstract}


Square Duque of Caxias, in Cáceres-MT, by a floristic survey and landscape analysis. A floristic survey was carried out in order to list all the plant species present in the area. The information was recorded in spreadsheets containing common name, scientific name, tree size (small, medium and large) and origin (native or exotic). The landscape analysis was performed by observation of the insertion of furniture, characteristic of the tree species and the soil cover. In the square there are 69 individuals of 18 different species, $66.7 \%$ of which are exotic, but it is always advisable to use native species. The most frequent species were: Licania tomentosa (Benth.) Fritsch (oiti), Delonix regia (Bojer ex Hook.) Raf. (flamboyant) and Roystonea oleracea (Jacq.) O.F. Cook (Imperial Palm). The distribution of the trees in the square occurs both in an isolated and grouped way, therefore, it has densely shaded areas, as well as areas where the bench are exposed to solar radiation, which determines their use by the population. In this way, it is suggested that native trees be planted in places with no vegetation in order to provide shade to the users, so that the square becomes more crowded.

KEYWORDS: Green areas; Floristic Survey; Public squares.

\section{INTRODUÇÃO}

Espaço ao ar livre e contato com a natureza são necessidades que os habitantes urbanos possuem, isso se deve pelo crescente distanciamento que as cidades passaram a ter em relação às áreas rurais. As dimensões territoriais e a variedade de atividades que nas cidades se desenvolvem, tornaram esse lugar a moradia da maior parte da humanidade (BEZERRA et al. 2016).

Desde a ascendência das cidades os espaços livres públicos têm grande importância para a vida urbana. Esses locais, especificamente os espaços verdes, de acordo com Nucci (2008), devem cumprir três funções (estética, ecológica e lazer), sendo que, no processo de planejamento sejam considerados, os elementos naturais, visando uma integração da natureza com o ser humano, tendo em vista que os espaços verdes são essenciais para a saúde, qualidade de vida e sustentabilidade.

Os principais elementos constituintes das áreas verdes são as árvores, elas desempenham um papel importante no ambiente citadino, pois fornecem uma gama de serviços ecossistêmicos (GU et al., 2015), como isolar o ruído (ROY et al., 2012), absorção do carbono através da fotossíntese (BOUKILI et al., 2017), diminuição da temperatura do ar, mitigando o efeito de ilha de calor urbana (SHIFLETT et al., 2017), diminui o risco de inundações (ZIMMERMANN et al., 2016) e fornece abrigos para a vida selvagem. Além desses muitos serviços ecológicos e ambientais, as árvores urbanas também fornecem importantes benefícios psicológicos e sociais.

Dentre as áreas de uso público, citam-se as praças, as quais podem proporcionar benefícios para o meio urbano, cuja qualidade do ambiente permite a permanência dos usuários no local e o desenvolvimento de atividades sociais (FLACH; BERDETE, 2016). As espécies florestais existentes nesses espaços melhoraram a qualidade ambiental, devido ao sombreamento proporcionado, especialmente no horário com maior incidência de radiação (OLIVEIRA et al., 2013).

A rica arborização de praças proporciona abrigo à avifauna, consequentemente uma variedade maior de espécies, influenciando positivamente no equilíbrio das cadeias alimentares e na diminuição de pragas e agentes vetores de doenças (ANDRADE; JERONIMO, 2015). As aves, por sua vez, transmitem harmonia aos visitantes, como também podem polinizar e dispersar sementes de diferentes espécies vegetais (SAMBURGO-SANTOS; ROSA, 2013). 
Cáceres foi elevada à categoria de cidade em 1874, suas primeiras praças possuem a nomeação de pessoas ilustres do município ou país, tais como: Barão do Rio Branco, Major João Carlos e Duque de Caxias, cujos nomes trazem o memorável dos discursos fundadores locais e nacionais. Ao lado da Praça Duque de Caxias está localizada a Escola Estadual "Esperidião Marques", criada em 1915, que compõe o conjunto de imóveis tombados do Centro Histórico da cidade. No centro da praça destaca-se a imagem de bronze de Duque de Caxias, instalada em sua homenagem, por significar na história do Brasil a figura do militar defensor do país (SILVA; ZATTAR, 2015).

A Praça Duque de Caxias possui abundante vegetação plantada ao longo de sua existência. É um local frequentado por moradores da região e pessoas que frequentam estabelecimentos que estão no entorno da praça. No entanto, análises sobre a composição florística e paisagística necessitam ser realizados, com vistas a subsidiar a gestão e manutenção desses espaços públicos. Diante do cenário exposto, se faz necessário um estudo sobre o componente arbóreo da praça, assim como se sua organização e distribuição cumpre sua função social e aos anseios da população.

Neste contexto, este trabalho objetivou identificar e quantificar as espécies arbustivas e arbóreas presente na Praça Duque de Caxias, em Cáceres-MT, como também realizar uma análise paisagística de modo a fazer inferência sobre à qualidade ambiental e cênica da mesma.

\section{MATERIAL E MÉTODOS}

O município de Cáceres-MT abrange os biomas Cerrado, Amazônia e Pantanal, sendo este último responsável por $50,87 \%$ da área do município (MIRANDA et al., 2018). O clima, segundo a classificação climática de Köppen é o tropical sub-úmido $(\mathrm{Aw})$, com temperatura média anual de $26,24^{\circ} \mathrm{C}$ e precipitação total anual de $1355 \mathrm{~mm}$, cujo período chuvoso se estende de dezembro a março.

A área escolhida para estudo é a Praça Duque de Caxias, popularmente conhecida como Praça Duque. Está localizada nas coordenadas $16^{\circ} 04^{\prime} 06^{\prime \prime} S$ $57^{\circ} 41^{\prime 2} 21^{\prime \prime} \mathrm{O}$, a $176 \mathrm{~m}$ de altitude (Figura 1). Possui formato retangular e área de $6.764,73 \mathrm{~m}^{2}$, sendo constituída por área cimentada, como também por área vegetada tanto por gramíneas, como por vegetação arbustiva e arbórea.

A coleta dos dados foi realizada através de visitas à Praça Duque, no mês de dezembro de 2015, ocasião em que foi realizado levantamento florístico com o intuito de listar todas as espécies vegetais presentes na área (inventário 100\% ou censo). As informações foram registradas em planilhas contendo nome vulgar, nome científico, porte das árvores (pequeno, médio e grande) e origem (nativa ou exótica).

Para isto, considerou-se como árvores, os indivíduos de caule lenhoso, tipo tronco e palmeiras, de caule tipo estipe, conforme classificação de Lorenzi (2002). As espécies que não foram identificadas no ato do inventário foram fotografadas e identificadas posteriormente através de consultas à literatura especializada, como Lorenzi (2002) e Almeida et al. (1998), e sites oficiais, como Trópicos e Flora do Brasil. 


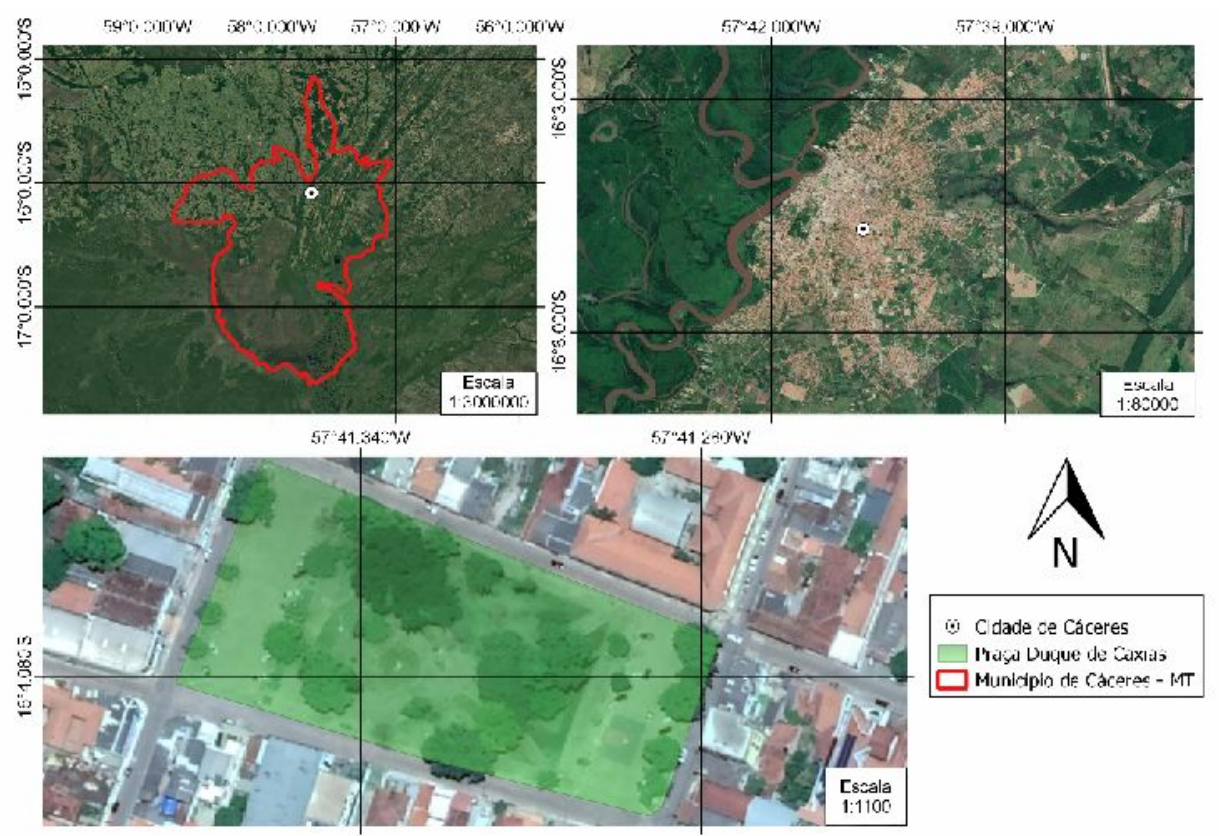

FIGURA 1. Mapa de localização da Praça Duque de Caxias, Cáceres-MT. FONTE: Os Autores, (2018)

O porte dos indivíduos foi classificado em pequeno, médio e grande, sendo que árvores de pequeno porte são aquelas que, na fase adulta atingem até $5 \mathrm{~m}$, e de médio porte são aquelas que, na fase adulta, atingem de 5 a $10 \mathrm{~m}$ de altura total. Árvores de grande porte, por sua vez, ultrapassam $10 \mathrm{~m}$ de altura na fase adulta, conforme manual de arborização urbana da Prefeitura Municipal de Natal (2009).

Após a coleta dos dados, os mesmos foram processados para a realização da análise descritiva, sendo agrupados por espécie e por origem (exóticas e nativas). Para verificar o número de vezes que os indivíduos de cada espécie foram observados na praça, calculou-se a frequência absoluta $\left(\mathrm{Fa}_{\mathrm{i}}\right)$ e a frequência relativa $\left(F r_{i} \%\right)$. Esta última corresponde à proporção do número de observações de uma determinada espécie em relação ao total de observações, sendo expressa em termos percentuais (Equação 1).

$$
F r_{i} \%=\frac{F a_{i}}{\Sigma_{i} F a_{i}}
$$

Em que:

$\mathrm{Fr}_{\mathrm{i}} \%=$ frequência relativa da espécie $\mathrm{n} ; \mathrm{e}$ $\mathrm{Fa}_{\mathrm{i}}=$ frequência absoluta da espécie $\mathrm{n}$.

$\mathrm{Na}$ ocasião do inventário, elaborou-se um croqui da praça, cujas árvores foram inseridas de acordo com sua localização na área estudada.

A análise paisagística foi realizada através de observação da inserção de mobiliários (bancos e luminárias), e característica das espécies arbóreas, no que se refere a distribuição dos indivíduos, se de forma isolada ou aglomerada e abscisão foliar, como também o revestimento do solo da praça (pavimentado ou vegetado) de forma a compreender a qualidade ambiental da praça em questão. 


\section{RESULTADOS E DISCUSSÃO}

\section{Levantamento Florístico}

No levantamento florístico foram identificados 69 indivíduos, de 18 espécies diferentes, sendo 12 exóticas e 6 nativas (Tabela 1), cuja distribuição está representada na figura 2. Desse total, as espécies Nerium oleander L., Lilium sp. e Ixora sp. são de porte arbustivo (Tabela 2). Dentre as espécies de porte arbóreo, as com maior número de indivíduos distribuídos na praça foram Licania tomentosa (Benth.) Fritsch (oiti), Delonix regia (Bojer ex Hook.) Raf. (flamboyant) e Roystonea oleracea (Jacq.) O.F. Cook (palmeira imperial), apresentando frequência de $25 \%$, $16,7 \%$ e $10 \%$, respectivamente.

TABELA 1. Relação de espécie, origem, frequência absoluta $\left(F a_{i}\right)$, e frequência relativa $\left(\mathrm{Fr}_{\mathrm{i}} \%\right)$ dos indivíduos arbóreos inventariados na Praça Duque de Caxias.

\begin{tabular}{|c|c|c|c|c|}
\hline $\begin{array}{c}\text { Nome } \\
\text { popular }\end{array}$ & Espécie & Origem & $\mathrm{Fa}_{\mathbf{i}}$ & $\mathrm{Fr}_{\mathrm{i}}(\%)$ \\
\hline Macaúba & $\begin{array}{l}\text { Acrocomia aculeata (Jacq.) Lood. ex } \\
\text { Mart. }\end{array}$ & nativa & 4 & 6,7 \\
\hline $\begin{array}{l}\text { Chuva de } \\
\text { ouro }\end{array}$ & Cassia fistula L. & exótica & 2 & 3,3 \\
\hline Sombreiro & Clitoria fairchildiana R.A. Howard & nativa & 1 & 1,7 \\
\hline Cica & Cycas sp. & exótica & 1 & 1,7 \\
\hline Flamboyant & Delonix regia (Bojer ex Hook.) Raf. & exótica & 10 & 16,7 \\
\hline Tamboril & $\begin{array}{l}\text { Enterolobium contortisiliquum (Vell.) } \\
\text { Morong }\end{array}$ & nativa & 1 & 1,7 \\
\hline figueirinha & Ficus benjamina L. & exótica & 4 & 6,7 \\
\hline Figueira & Ficus sp. & exótica & 4 & 6,7 \\
\hline & Licania tomentosa (Benth.) Fritsch & nativa & 15 & 25,0 \\
\hline Faveiro & $\begin{array}{l}\text { Peltophorum dubium (Sprengel) } \\
\text { Taubert }\end{array}$ & exótica & 1 & 1,7 \\
\hline $\begin{array}{l}\text { Palmeira } \\
\text { imperial }\end{array}$ & Roystonea oleracea (Jacq.) O.F. Cook & exótica & 6 & 10,0 \\
\hline $\begin{array}{l}\text { Cássia de } \\
\text { sião }\end{array}$ & $\begin{array}{l}\text { Senna siamea (Lam.) Irwim \& } \\
\text { Barneby. }\end{array}$ & exótica & 1 & 1,7 \\
\hline Mogno & Swietenia macrophylla King & nativa & 3 & 5,0 \\
\hline Ipê & Tabebuia sp. & nativa & 4 & 6,7 \\
\hline Sete copas & Terminalia catappa L. & exótica & 3 & 5,0 \\
\hline
\end{tabular}

TABELA 2. Relação de espécie, número de indivíduos, origem e frequência de indivíduos arbustivos inventariados na Praça Duque de Caxias.

\begin{tabular}{llccc}
\hline Nome popular & \multicolumn{1}{c}{ Espécie } & Origem & $\mathbf{F a}_{\mathbf{i}}$ & $\mathbf{F r}_{\mathbf{i}}(\%)$ \\
\hline Ixora & Ixora sp. & exótica & 2 & 22,2 \\
Lírio & Lilium sp. & exótica & 3 & 33,3 \\
Espirradeira & Nerium oleander L. & exótica & 4 & 44,4 \\
\hline Total & & & 9 & 100
\end{tabular}




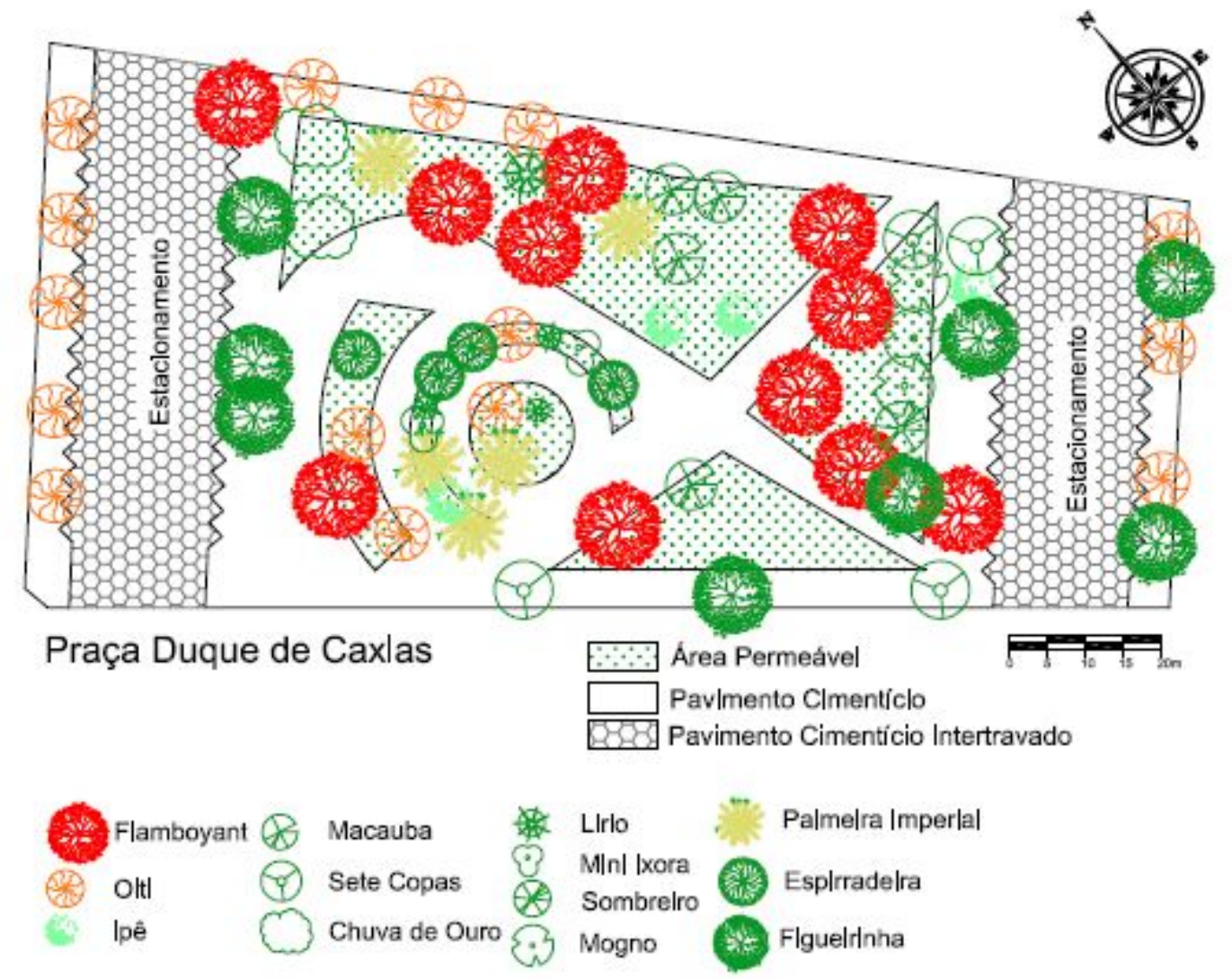

FIGURA 2. Croqui de distribuição dos indivíduos arbustivos e arbóreos na Praça Duque de Caxias, Cáceres-MT. FONTE: Os autores (2018).

Pode-se notar que existem poucos indivíduos de porte arbustivo nesta praça (9 indivíduos). Dentre elas, a que apresentou maior número de exemplares foi a $N$. oleander, com 4 indivíduos. A espécie $N$. oleander é uma planta tóxica tanto para humanos quanto para animais (PEDROZA et al., 2014), não sendo recomendada o uso na arborização urbana. Dessa forma, seria interessante a substituição desta espécie por outra que não apresente potencial toxicológico.

Miller et al. (2015) recomendam que as espécies de maior frequência na arborização urbana, não ultrapassem $15 \%$ do total, pois quanto maior a porcentagem de uma única espécie, maiores são as chances de ocorrência de pragas e doenças. Dessa forma, a distribuição dos indivíduos de $D$. regia e $L$. tomentosa na Praça Duque de Caxias estão acima do recomendado por estes autores, apresentando frequência de $16,7 \%$ e $25 \%$, respectivamente.

Em um inventário quantitativo de espécies presentes nas praças centrais da cidade de Cáceres-MT, Assunção et al. (2014) constataram a predominância das seguintes espécies: oiti $(18,2 \%)$, palmeira imperial $(16,5 \%)$, cambará $(11,3 \%)$, ipê $(9,1 \%)$ e macaúba $(8,2 \%)$. Em estudo realizado por Almeida e Neto (2010), a espécie $L$. tomentosa também apresentou maior frequência na arborização viária, sendo 39,5\% e 82,48\% nas cidades de Matupá-MT e Colíder-MT, respectivamente.

O número de espécies exóticas na Praça Duque de Caxias superou o número de nativas, apresentando um percentual de $66,7 \%$ de exóticas. Ferraz et al. (2017) também constaram que $74,0 \%$ de espécies plantadas numa praça de São Paulo são exóticas. Assunção et al. (2014) ao estudarem as praças da região central de Cáceres-MT, perceberam que o percentual de espécies exóticas foi $16 \%$ superior ao 
de nativas. Sendo assim é aconselhável sempre o uso de espécies nativas, sempre priorizando as espécies endêmicas dos biomas pantanal e cerrado, no caso da cidade de Cáceres-MT, pois favorecem a manutenção da biodiversidade local.

Do total de indivíduos arbóreos presentes na praça, 46,67\% são nativos, destes, apenas 12 indivíduos são de ocorrência no Cerrado e no Estado de Mato Grosso. Os demais, pertencentes às espécies C. fairchildiana, ocorrem no Cerrado, mas não possui ocorrência confirmada em Mato Grosso e L. tomentosa, que ocorre no bioma Mata Atlântica (FLORA DO BRASIL, 2016).

A baixa diversidade de espécies nativas na arborização urbana pode ser em decorrência da preferência por espécies de outras regiões do país ou de outros países. Isso pode ser explicado pelo baixo conhecimento ecológico e silvicultural das espécies nativas ou pela escolha de espécies que são difundidas na arborização urbana de outros locais (GONÇALVES; PAIVA, 2004).

Embora o número de indivíduos exóticos na Praça Duque de Caxias seja mais elevado que o de nativas, os mesmos não apresentam características de invasoras potenciais, como rápido desenvolvimento, alto potencial de dispersão e adaptação, tendo em vista que não foram encontrados indivíduos jovens das espécies exóticas, ocorrendo espontaneamente na área.

Quanto ao porte dos indivíduos, a maioria apresentou porte médio a grande (Tabela 3), sendo que apenas plantas de D. regia, F. benjamina e Ficus sp., apresentaram pequeno porte no período de avaliação, apresentando 10, 25 e 25\%, respectivamente de indivíduos enquadrados nessa categoria.

TABELA 3. Porcentagem de árvores de pequeno, médio e grande porte da Praça Duque de Caxias, Cáceres-MT.

\begin{tabular}{lccc}
\hline \multicolumn{1}{c}{ Espécie } & \multicolumn{2}{c}{ Porte (\% de indivíduos) } \\
& Pequeno & Médio & Grande \\
\hline $\begin{array}{l}\text { Acrocomia aculeata (Jacq.) Lood. ex Mart. } \\
\text { Cassia fistula L. }\end{array}$ & & 100 & 100 \\
Clitoria fairchildiana R.A. Howard & 10 & 100 & \\
Delonix regia (Bojer ex Hook.) Raf. & & & 70 \\
Enterolobium contortisiliquum (Vell.) Morong & 25 & 75 & 100 \\
Ficus benjamina L. & 25 & 25 & 50 \\
Ficus sp. & & 36 & 64 \\
Licania tomentosa (Benth.) Fritsch & & & 100 \\
Peltophorum dubium (Sprengel) Taubert & & & 100 \\
Roystonea oleracea (Jacq.) O.F. Cook & & 25 & 100 \\
Senna siamea (Lam.) Irwim \& Barneby. & & 100 & 75 \\
Swietenia macrophylla King. & & & \\
Tabebuia sp. & & & \\
Terminalia catappa L. & & & \\
\hline
\end{tabular}

O porte das árvores é uma das características importantes quando se trata de atenuação dos efeitos do clima. Para Oliveira et al. (2013), o sombreamento proporcionado por árvores é um dos fatores determinantes no conforto térmico em regiões de clima tropical.

Existe uma diversidade de densidade e formato de copas, que garantem diferentes níveis de sombreamento, esses fatores devem ser observados 
criteriosamente pelos planejadores urbanos, considerando a compatibilidade com as condições climáticas dos locais aonde serão inseridas as espécies (MALAMUT, 2011). Da mesma maneira, é importante observar as mudanças de forma e tamanho que ocorrerão com o passar dos anos, notando o dimensionamento do ambiente e condições de insolação às quais as árvores estarão submetidas (MASCARÓ; MASCARÓ, 2010).

No meio urbano, as espécies de grande porte são mais eficientes na atenuação do microclima, quando comparadas às espécies de pequeno porte. Nesse sentido, pode-se inferir que a maioria dos indivíduos arbóreos da Praça Duque de Caxias apresentam porte capaz de causar alterações no ambiente térmico do local.

\section{Análise paisagística}

$\mathrm{Na}$ Praça Duque de Caxias, os canteiros e a área pavimentada estão nivelados e separados por bancos de concreto (Figura 3B). A área pavimentada por sua vez, é constituída por paralelepípedos, que são destinados à circulação dos usuários e o interior dos canteiros é composto por gramíneas (Figura 3A). A gramínea, além de recobrir o solo, valoriza a paisagem por sua cor e contraste com a cor cinza dos paralelepípedos. No entanto, em alguns lugares, devido ao sombreamento excessivo, a gramínea não sobreviveu. Assim, seria interessante o uso de espécie de forrações compatíveis ou adaptadas ao sombreamento.

Dessa forma, os espaços que serão ocupados por espécies vegetais devem ser escolhidos de acordo com sua funcionalidade, seja para delimitar acesso aos transeuntes ou garantir sombra para determinadas atividades e, além disso, devem ser em função da paisagem que se deseja obter. Esses espaços, denominados canteiros, podem estar nivelados ou desnivelados com o piso e separados por alguma barreira de contenção (GATTI, 2013).
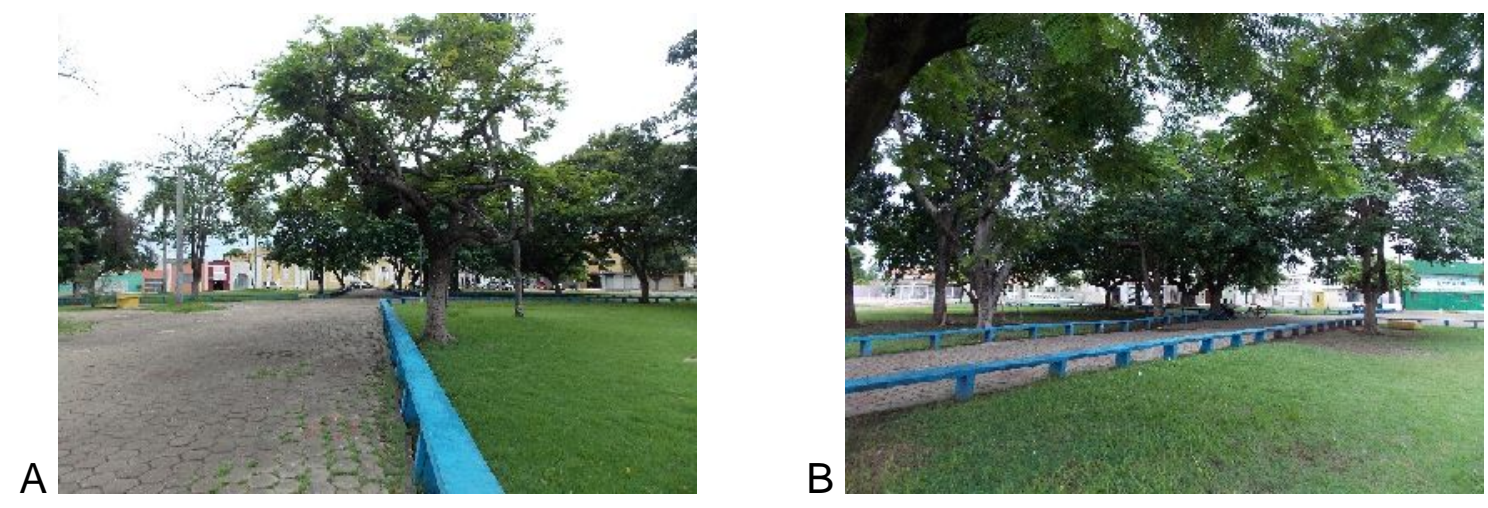

FIGURA 3. (A)- Revestimento do solo na Praça Duque de Caxias, Cáceres-MT; (B)bancos delimitando os canteiros na Praça Duque de Caxias, CáceresMT.

FONTE: Os autores (2015)

Além disso, o solo coberto por gramíneas tende a apresentar microclima mais suave e estável devido ao albedo ser maior (média de 22,5\%) que a superfície escura e seca (14\%) (AYOADE, 1996), pois quanto maior o albedo, maior a capacidade de reflexão dos raios solares. Dessa forma, essas áreas podem proporcionar sensação de bem-estar aos usuários. 
No período noturno, o interior da Praça Duque de Caxias, e o estacionamento são bem iluminados, somando 38 luminárias. Fator este, primordial para a permanência dos visitantes neste espaço de uso público. O mobiliário de uma praça marca a identidade da mesma, podendo ser constituído por bancos, lixeiras, luminárias, brinquedos infantis, guarda-corpos, e dentre outros (GATTI, 2013).

Os equipamentos e serviços disponíveis nas praças, como também, o conforto experimentado pelos usuários determina a visita ou permanência dos mesmos nesses locais. A existência de bancos em locais adequado e sombreado os tornariam mais frequentados. O fato da praça possuir estacionamento também se torna um ótimo atrativo (OLIVEIRA et al., 2013).

Em uma futura revitalização da Praça Duque de Caxias sugere-se a distribuição de lixeiras em pontos estratégicos, para que a população não jogue lixo nas imediações da mesma, como também, instalação de brinquedos infantis. Ações como essas podem intensificar o uso da praça, tornando-as mais atrativa.

O manejo dos indivíduos arbóreos também deve ser levado em consideração nas práticas de manutenção da praça, pois percebe-se a presença de indivíduos arbóreos mortos em pé e a queda de alguns galhos, o que pode provocar acidentes com os usuários e transeuntes.

Na Praça Duque de Caxias, o mobiliário de lazer é composto basicamente por bancos contínuos, cujos mesmos delimitam todos os canteiros do local (Figura 3B). Além destes, existem os bancos convencionais nas extremidades da praça, situados sob a copa das árvores. Apesar da abundância de assentos, parte dos bancos estão expostos ao sol, o que os tornam inutilizáveis, principalmente no período mais quente do dia. Entretanto, os localizados sob a copa das árvores são bastante utilizados pela população no período diurno, devido à sensação de bem-estar proporcionada pelas árvores. Em estudo realizado em Curitiba na Praça Tiradentes, as características mais percebidas pelos usuários do local foram, a limpeza, o conforto para prática de lazer passivo e a vegetação em quantidade suficiente para tornar o espaço agradável à permanência (ROSANELI et al. 2016).

Outro fator que pode influenciar o uso dos assentos é o seu estado de conservação, pois a condição em que eles se apresentam podem transmitir maior ou menor segurança para os usuários se acomodarem. Na praça estudada, este não é um empecilho para os usuários, já que os bancos apresentaram ótimo estado de conservação.

Assim como os assentos, a arborização também é um dos pontos chaves para a permanência das pessoas na praça, seja para o descanso sob à sombra, ou simplesmente para contemplação. $\mathrm{Na}$ etapa do planejamento, os espaços destinados à arborização podem ser sobrepostos aos demais tipos de vegetação (GATTI, 2013). No caso da Praça Duque de Caxias é possível verificar duas áreas com maior concentração de indivíduos arbóreos (Figura 4), plantados nos canteiros gramados. Ambas proporcionam bastante sombra, constituindo áreas propícias ao uso pelos habitantes e visitantes. 


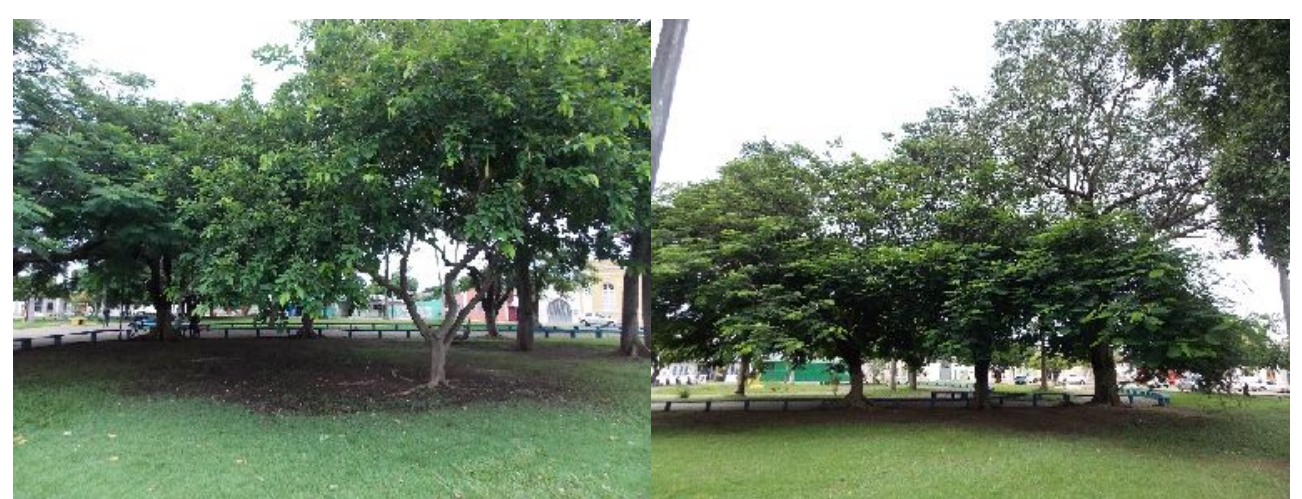

FIGURA 4. Concentração de indivíduos arbóreos em dois pontos da Praça Duque de Caxias, Cáceres-MT.

FONTE: Os autores (2015)

Além dessas áreas de maior concentração arbórea, há árvores plantadas isoladamente no interior da praça, como também, locais desprovidos de vegetação arbórea, os quais proporcionam menor área sombreada. Sugere-se que nas próximas manutenções e reformas da praça, a gestão pública invista no plantio de mudas, tanto nas áreas ociosas, quanto próximas às árvores mortas.

A composição florística de uma praça desempenha papel muito importante no fornecimento de serviços ambientais, como sombra aos usuários, relacionada ao conforto térmico. Em cidades de clima frio, a escolha de espécies caducifólias (que perdem suas folhas na estação seca) é fundamental para o aproveitamento da radiação solar nos dias frios, já cidades com temperaturas mais elevadas, as espécies perenifólias (árvores que mantêm suas folhas durante o ano todo) são mais apropriadas.

Oliveira et al. (2013) indicam o plantio de espécies perenifólias em locais onde a radiação solar é intensa e a temperatura é elevada durante praticamente todo ano, como por exemplo o município de Cáceres, que possui temperatura média anual de $26,24{ }^{\circ} \mathrm{C}$. Na Praça Duque de Caxias, grande parte as árvores plantadas são caducifólias (Figura 5): ipê, mogno, sombreiro, tamboril (LORENZI, 2002), flamboyant, chuva de ouro, sete copas e faveiro. Apesar de perderem suas folhas por um determinado período, produzem flores, as quais são de notável beleza cênica, servindo de atrativo para as populações local e visitante.

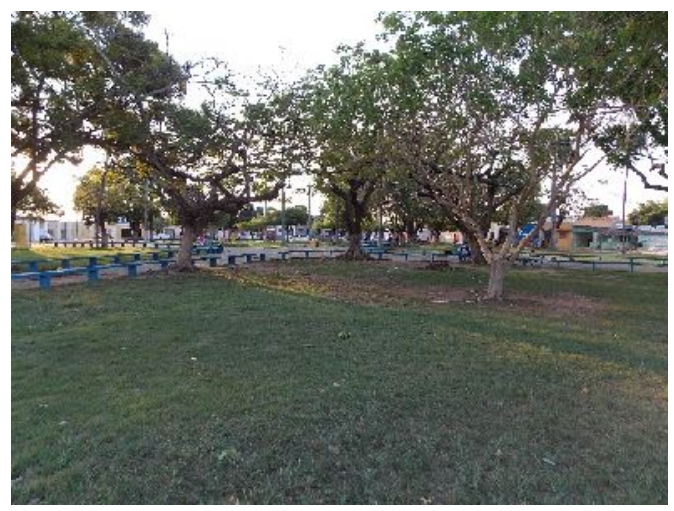

FIGURA 5. Espécies florestais praticamente sem folhas no período da seca na Praça Duque de Caxias, Cáceres-MT.

FONTE: Os autores (2015) 
Neste sentido, a Praça Duque de Caxias possui como aspectos positivos, a presença de sombreamento, bancos, luminárias, e estacionamento, o que possibilita a população usufruir desses benefícios, sendo ambiente para descontração e lazer.

\section{CONCLUSÃO}

A praça Duque de Caxias apresentou um total de 69 indivíduos florestais, sendo $66,7 \%$ de espécies exóticas, no entanto é aconselhável sempre o predomínio de uso de espécies nativas. Dentre as espécies de porte arbóreo, as que apresentaram maior número de indivíduos foram Licania tomentosa (Benth.) Fritsch (oiti), Delonix regia (Bojer ex Hook.) Raf. (flamboyant) e Roystonea oleracea (Jacq.) O.F. Cook (palmeira imperial), apresentando frequência de 25\%, 16,7\% e 10\%, respectivamente.

A maior parte das árvores presentes na praça são de médio a grande porte, sendo que apenas exemplares de D. regia, F. benjamina e Ficus sp. apresentaram pequeno porte (10, 25 e 25\% respectivamente). Assim, recomenda-se o plantio de mudas para suprir possíveis mortes de indivíduos adultos.

A arborização presente na praça juntamente com o imobiliário proporciona um ambiente agradável à população e aos visitantes, devido aos assentos sob sombreamento e iluminação no período noturno, transmitindo sensação de conforto e segurança. No entanto, sugere-se a inserção de área de lazer para crianças e plantio de árvores nativas em áreas menos arborizadas, de forma que intensifique o uso da praça Duque de Caxias.

\section{AGRADECIMENTOS}

À Fundação de Amparo à Pesquisa do Estado de Mato Grosso (FAPEMAT) pela concessão de bolsa de Iniciação científica para realização desta pesquisa.

\section{REFERÊNCIAS}

ALMEIDA, S. P.; PROENÇA, C. E. B.; SANO, S. M.; RIBEIRO, J. F. Cerrado: espécies vegetais úteis. Planaltina, DF: EMBRAPA-CPAC, 1998. 464 p.

ALMEIDA, D.N.; RONDON NETO, R.M. Análise da arborização urbana de duas cidades da região norte do Estado de Mato Grosso. Revista Árvore, Viçosa, v. 34, n. 5, p. 899-906, 2010. Disponível em: < http://www.scielo.br/scielo.php?script=sci_arttext\&pid=S0100-67622010000500015>. Acesso em: 23 ago. 2018. doi:10.1590/S0100-67622010000500015.

ANDRADE, M. N. M. M.; JERONIMO, C. E. de M. Diagnóstico da arborização do espaço urbano da cidade de João Pessoa, PB. Revista Eletrônica em Gestão, Educação e Tecnologia Ambiental, Santa Maria, v. 19, n. 3, p. 194-208, 2015. Disponível em: < https://periodicos.ufsm.br/reget/article/viewFile/17785/pdf>. Acesso em 23 ago. 2018. doi: 105902/2236130817785.

ASSUNÇÃO, K. C.; LUZ, P. B.; NEVES, L. G.; SOBRINHO, S. P. Levantamento quantitativo da arborização de praças da cidade de Cáceres/MT. Revista da Sociedade Brasileira de Arborização Urbana, v. 9, n. 1, p. 123-132, 2014. Disponível em: <https://dadospdf.com/downloadFile/5a4cf665b7d7bcab672c0fa3> Acesso em 19 ago. 2018. 
AYOADE, J. O. Introdução à climatologia para os trópicos. Rio de Janeiro: Bertrand Brasil, 1996. $332 \mathrm{p}$.

BEZERRA, M. do C. L.; DA ROCHA, M. A.; BOGNIOTTI, G. M. C. Qualidade dos espaços verdes urbanos: o papel dos parques de lazer e de preservação - Revista eletrônica de Arquitetura e urbanismo, n. 15, p. 128-142, 2016. Disponível em $<$ http://www.usjt.br/arq.urb/numero-15/8-maria-do-carmo-bezerra.pdf>. Acesso em 13 set. 2018.

BOUKILI, V. K. S.; BEBBER, D. P.; MORTIMER, T.; VENICX, G.; LEFCOURT, D.; CHANDLER, M.; EISENBERGA, C. Assessing the performance of urban forest carbon sequestration models using direct measurements of tree growth. Urban Forestry \& Urban Greening, v. 24, p. 212-221, 2017. Disponível em: <https://doi.org/10.1016/j.ufug.2017.03.015>. Acesso em 22 ago. 2018. doi: 10.1016/j.ufug.2017.03.015.

FERRAZ, M. V.; DEL NERI, L. A; NUNES, J. V. C. Levantamento florístico das espécies utilizadas na ornamentação da praça cidade Nakatsugawa, Registro, SP. Revista Tree dimensional, v.2 n. 4, p. 45, 2017. Disponível em: <http://www.treedimensional.org/revista/2017b/levantamento.pdf>. Acesso em 19 ago. 2018. doi: 10.18677/TreeDimensional_2017B4.

FLACH, C. W.; BERDETE, M. M. Praças, Parques e Avenidas: áreas verdes e sua importância como espaço de lazer em Pelotas. Ciência e Natura, Santa Maria, v. 38 n. $1, \quad$ p. 195-205, 2016. Disponível em: $<$ https://periodicos.ufsm.br/cienciaenatura/article/viewFile/19018/pdf >. Acesso em 10 set. 2018. doi:10.5902/2179-460X19018.

FLORA DO BRASIL. Jardim Botânico do Rio de Janeiro. Disponível em: < http://floradobrasil.jbrj.gov.br>. Acesso em: 20 jan. 2016.

GATTI, S. Espaços Públicos: diagnóstico e metodologia de projeto. São Paulo: ABCP, 2013. $91 \mathrm{p}$.

GONÇALVES, W.; PAIVA, H. N. Árvores para ambiente urbano. Viçosa: Editora UFV, 2004. 242 p. (Coleção Jardinagem e Paisagismo, n. 2).

GU, H.; SINGH, A.; TOWNSEND, P. Detection of gradients of forest composition in an urban area using imaging spectroscopy. Remote Sensing of Environment, v. 167, p. 168-180, 2015. Disponível em: <https://doi.org/10.1016/j.rse.2015.06.010>. Acesso em 22 ago. 2018. doi: 10.1016/j.rse.2015.06.010

LORENZI, H. Árvores brasileiras: manual de identificação e cultivo de plantas arbóreas do Brasil. vol. 1, 2 ed. Nova Odessa: Editora Instituto Plantarum, 2002.

MALAMUT, Marcos. Paisagismo: Projetando espaços livres. Lauro de Freitas: Livro.com, n. 1, 2011. 148 p.

MASCARÓ, L.; MASCARÓ, J. L. Vegetação Urbana. n. 3. Porto Alegre: Masquatro, 2010. 212 p. 
MILLER, R. W.; HAUER, R. J.; WERNER, L. P. Urban forestry: planning and managing urban greenspaces. 3 ed. Long Grove: Waveland Press, Inc, 2015.

MIRANDA, M. R. S.; NEVES, L. F. S.; KREITLOW, J. P.; NEVES, S. M. A. S.; NEVES, R. J. Distribuição de queimadas e mudanças na cobertura vegetal e uso da terra no Bioma Pantanal, Cáceres-Brasil. Revista Caminhos de Geografia, v. 19, n. 65, p. 91-108, 2018. Disponível em: <http://www.seer.ufu.br/index.php/caminhosdegeografia/>. Acesso em: 18 ago. 2018. doi: 10.14393/RCG196508

NATAL. Prefeitura Municipal. Secretaria Municipal de Meio Ambiente e Urbanismo. Manual de arborização urbana de Natal. Secretaria Municipal de Meio Ambiente e Urbanismo, Natal: SEMURB, 2009. Disponível em: $<$ file:///C:/Users/ferna/Downloads/Manual_de_Arborizacao.pdf>. Acesso em 15 ago. 2018.

NUCCI, T. C. Qualidade Ambiental e Adensamento Urbano: um estudo de ecologia e planejamento da paisagem aplicada ao distrito de Santa Cecília (MSP). 2 ed. Curitiba: o autor, 2008.

OLIVEIRA, A. S.; SANCHES, L.; MUSIS, C. R.; NOGUEIRA, M. C. J. A. Benefícios da arborização em praças urbanas - o caso de Cuiabá/MT. Revista Eletrônica em Gestão, Educação e Tecnologia Ambiental, v. 9, n. 9, p. 1900-1915, 2013. Disponível em: <https://periodicos.ufsm.br/reget/article/viewFile/7695/pdf>. Acesso em 26 ago. 2018. doi: 10.5902/223611707695.

PEDROZA, H. P.; FERREIRA, M. G.; CARVALHO, J. G.; MELO, K. D. A; KELLER, K. M., MELO; et al. Concentrações de oleandrina nas folhas de Nerium oleander de diferentes cores da floração. Ciência Rural, v. 45, n. 5, p. 864-866, 2015. Disponível em: <http://dx.doi.org/10.1590/0103 8478cr20140885>. Acesso em 18 ago. 2018. doi: 10.1590/0103-8478cr20140885

PINHEIRO, C. R.; SOUZA, D. D. A importância da arborização nas cidades e sua influência no microclima. Revista Gestão \& Sustentabilidade Ambiental, v. 6, n. 1, p. 67-82, 2017. Disponível em: <www.portaldeperiodicos.unisul.br/index.php/gestao_ambiental/article/.../3066>. Acesso em 26 ago. 2018. doi: http://dx.doi.org/10.19177/rgsa.v6e1201767-82.

ROSANELI, A. F.; FRÓES, A. C. S.; FURLAN, D. L. S.; GONÇALVES, F. T.; SENGER, S. Apropriação do espaço livre público na metrópole contemporânea: o caso da Praça Tiradentes em Curitiba/PR. URBE - Revista Brasileira de Gestão Urbana, v. 8, n. 3, p. 359-374, 2016. Disponível em: <http://www.scielo.br/pdf/urbe/v8n3/2175-3369-urbe-2175-3369008003AO06.pdf>. Acesso em: 14 ago. 2018. doi:10.1590/2175-3369.008.003.AO06.

ROY, S.; BYRNE, J; PICKERING C. A systematic quantitative review of urban tree benefits, costs, and assessment methods across cities in different climatic zones. Urban Forestry and Urban Greening, v. 11, n. 4, p. 351-363, 2012. Disponível em: 
<https://doi.org/10.1016/j.ufug.2012.06.006>. Acesso em 22 ago. 2018. doi: 10.1016/j.ufug.2012.06.006.

SAMBURGO-SANTOS; P. T.; ROSA, T. A. O. A arborização urbana como complemento de fontes alimentares para as aves. Arquivos do Museu Dinâmico Interdisciplinar, v. 17, n. 1, p. 9-10, 2013. Disponível em: < http://periodicos.uem.br/ojs/index.php/ArqMudi/article/view/23270/12496> Acesso em 15 out. 2018. doi: http://dx.doi.org/10.4025/arqmudi.v17i1 .

SHIFLETT, S. A.; LIANG, L. L.; CRUM, S. M.; FEYISA, G. L.; WANG, J.; G. JENERETTE, G. D. Variation in the urban vegetation, surface temperature, air temperature nexus. Science of the Total Environment, v. 579, p. 495-505, 2017. Disponível em: <https://doi.org/10.1016/j.scitotenv.2016.11.069>. Acesso em 22 ago. 2018. doi: 10.1016/j.scitotenv.2016.11.069.

SILVA, L. C.; ZATTAR, N. As diferentes formas de uso das praças nos espaços da cidade. Revista de Estudos Acadêmicos de Letras, v. 08 n. 02, p. 61-72, 2015. Disponível em: <file:///C:/Users/ferna/Downloads/915-3118-1-PB.pdf>. Acesso em 13 set. 2018.

TROPICOS.ORG. Jardim Botânico de Missouri. Disponível em: $<$ http://www.tropicos.org/>. Acesso em jan. 2016.

ZIMMERMANN, E.; BRACALENTI, L.; PIACENTINI, R.; INOSTROZA, L. Urban flood risk reduction by increasing green areas for adaptation to climate change. Procedia Engineering, v. 161, p. 2241-2246, 2016. Disponível em: <https://doi.org/10.1016/j.proeng.2016.08.822>. Acesso em 22 ago. 2018. doi: 10.1016/j.proeng.2016.08.822. 